\title{
Research
}

\section{Evidence-based medicine: a conflict between rigour and reality}

Kate Baxter, Department of Social Medicine, University of Bristol, Bristol, Helen Stoddart, Division of Primary Care, University of Bristol, Bristol, and Gwyn Bevan, Department of Operational Research, London School of Economics, London, UK

\begin{abstract}
The current government has given priority to two different objectives in reorganizing the National Health Service (NHS) in England and Wales. The first objective is to create a primary care-led NHS by organizing commissioning of hospital and community health services by new primary care organizations. The second objective is to improve quality and performance in the NHS and to assess this using evidence in various ways. Previous research has suggested that the changes GPs wish to make to services are often not based on published evidence. This suggests a conflict between the two principal objectives intended to drive the reorganization of the NHS. The aim of this study was therefore to explore these issues further. An interviewer-administered questionnaire survey was conducted on one general practitioner and one public health physician from each of four total purchasing pilots (TPPs) in Wales and their four host health authorities, respectively. The main outcome measures were the types of evidence used, and the extent to which evidence impacted on decisions. Access to evidence and views about its usefulness are also reported. It was found that more high-quality evidence was used in support of disease-specific than in support of nondisease-specific changes to care. Evidence played a greater role in decisions to change services that were purchased by health authorities, or provided by TPPs, than it did in changes to services purchased by TPPs. Similarly, higher quality of evidence was used when making decisions to change services that were purchased by health authorities or provided by TPPs, than for services that were purchased by TPPs. It is concluded that there is a mismatch between the availability of conventional, diseasespecific evidence directed at the delivery of care, and the need for other kinds of evidence for commissioning changes in the organization of care. This means that we need research and development to develop new methods and new types of evidence so that we can assess the benefits of commissioning in a primary care-led NHS.
\end{abstract}

Key words: commissioning; evidence-based medicine; primary care

\section{Introduction}

The present Government has given priority to two different objectives in reorganizing the National Health Service (NHS) in England (Department of Health, 1997) and Wales (Department of Health,

Address for correspondence: Kate Baxter, Department of Social Medicine, University of Bristol, Canynge Hall, Whiteladies Road, Bristol BS8 2PR, UK.

Email: c.baxter@bris.ac.uk

(C)Arnold 2001 1998a). One objective is to create a primary careled NHS by organizing commissioning of hospital and community health services by primary care groups (PCGs) in England and local health groups (LHGs) in Wales. These new primary care bodies are organized around general practices that will continue to provide primary care services for their registered populations (and some will take over the provision of community services). The second objective is to improve quality and performance in the NHS and to assess this using evidence in vari1463-4236(2001)PC035OA 
ous ways. The innovations directed at this objective include the National Institute of Clinical Excellence (NICE), National Service Frameworks, the concept of clinical governance, the Commission for Health Improvement, the National Performance Assessment Framework and a series of health outcome indicators (NHS Executive, 1999).

Total purchasing pilots (TPPs) were either single general practices or groups of general practices which had been fundholders, and which had opted to extend their commissioning role. GP fundholding covered a limited range of services. By opting for total purchasing, GPs could choose to make changes by commissioning from the full set of hospital and community health services. TPPs are thus the closest model to PCGs and LHGs to have been evaluated. This paper is an outcome of that evaluation, and it represents part of a research programme co-ordinated by the Total Purchasing National Evaluation Team (TP-NET). It examines the use of evidence when making changes to the commissioning of services by four TPPs in Wales. The objective of this research was to explore a discrepancy - which was revealed in an earlier study of TPPs (Killoran et al., 1999) - between the nature of these changes and conventional definitions of evidence. We shall explain the nature of this conflict here in order to set the context for what follows. In our discussion we shall consider how this problem creates a conflict between the two main objectives of the recent reorganization of the NHS.

The changes that TPPs wanted to achieve through commissioning were typically organizational (e.g., reductions in lengths of stay, or moving services closer to the local community) (Mays et al., 1997). This creates four types of problem in relation to most research and conventional definitions of evidence.

- Research is dominated by studies of clinical care in hospital rather than by changes in the organization of services and community-based care. Similarly, the standard definition of evidencebased medicine is the "conscientious, explicit and judicious use of current best evidence in making decisions about the care of individual patients' (Sackett et al., 1996). This is usually interpreted as the clinical care of patients, rather than the location or mode of delivery.

- Evidence in the conventional sense supports clinical improvements in the treatment of disease, both through the published results of randomized controlled trials or meta-analyses, and increasingly through economic evaluations and qualitative research. It is this type of published and easily interpreted evidence that is being implicitly advocated by the Government through its implementation of the targets and frameworks outlined above. This does not relate to the changes in the organization of care that GPs sought to make in commissioning.

- Although studies have shown that evidence was used to support the majority of interventions in secondary and primary care (Ellis et al., 1995; Gill et al., 1996), these studies are about provision rather than the commissioning of care. The use of evidence in commissioning has been shown to be patchy at best (Stocking, 1995).

- The nature of general practice is that when GPs take on commissioning they lack both the time and the skills to access information on effectiveness in the form of published research, and they are influenced by experience and hunch (Farmer and Williams, 1997; Lehman, 1999). Farmer and Williams also reported GPs' extensive use of their own practice-based data and information from their secondary-care providers.

It is thus not surprising that our previous work indicated that many changes made by all 53 English and Scottish TPPs lacked good evidence in the way in which this is commonly understood (Mahon et al., 1998). This finding emerged from researchers from five centres using a standard set of open-ended questions with the objective of obtaining a fully representative survey. However, this meant that it was difficult to extract a detailed understanding of the use of evidence in commissioning from these findings, due to both the complexity of the subject and the large numbers of interviewers involved. We therefore planned this small study of four TPPs in Wales in order to explore the use of evidence in commissioning by GPs by interviewing GPs and public health physicians.

\section{Methods}

A GP from each of four TPPs was interviewed in spring 1998. One pilot was a single practice, and

Primary Health Care Research and Development 2001; 2: 7-24 
the other three were groups of practices (with populations ranging from 19250 to 88600 ). One GP was a 'TPP-led' general practitioner, while the other three had an interest in the use of evidence, or had developed a working relationship with their local public health medicine department. One public health physician from each associated health authority who was leading the work with the pilot was interviewed. Three of these individuals were consultants and one was a trainee.

This paper reports the results with regard to their knowledge of the available evidence and its use in decision making. Each interviewee was sent the following definition of evidence-based medicine, adapted from Sackett et al. (1996) to be relevant to both purchasers' and providers' health care services. They were reminded of this at the beginning of the interview.

Evidence-based medicine is defined as the conscientious, explicit and judicious use of current best evidence in making decisions about the care of individual patients or when purchasing care for groups of patients. It involves tracking down the best external evidence with which to answer clinical or purchasing questions, critically appraising this evidence and using it to inform decisionmaking or practice (e.g., systematic reviews in which published and unpublished studies are used).

Respondents answered a series of open-ended and closed questions in face-to-face interviews using the format set out in the Appendix. The interviewer recorded the responses to closed questions on the pro forma, and these responses were analysed quantitatively.

Responses to open-ended questions were transcribed nonverbatim and used to add depth to responses about the interviewees' views of evidence and constraints in its use. The interview questions and pro formas were developed from a postal questionnaire sent to GPs throughout the UK, and were piloted by GP colleagues in Bristol.

Respondents were asked to describe three changes to purchased services that had taken place over the last 2 years. As each TPP was at a different stage of development, this period covered either preparatory or live years, or a mixture of both. TPP respondents also gave three examples of changes in provided services that had occurred during this period. Purchased service changes were defined as changes in health care purchased from other providers. Changes to provided services were described as policy changes in the treatment and care provided by themselves for individual patients. For each example, respondents indicated their perception of the contribution of evidence to the change on a four-point scale (the total reason, a large impact, a moderate impact, or little or no impact on the change). The source of the evidence was requested, and the types of evidence used to support each service change were documented.

The types of evidence cited by the respondents varied. It was not possible to categorize the evidence by quality using a standard hierarchy of randomized controlled trials, other types of trial, cohort studies and case-control studies (NHS Centre for Reviews and Dissemination, 1996). Indeed, in relation to decision making for purchasing and providing, the use of a standard hierarchy is too narrow, relying very much on published, quantitative studies. Decisions about service provision are more likely to require information from other areas, such as needs assessments, qualitative research and economic evaluations. We therefore produced a hierarchy of evidence comprising four levels (published trials or reviews, expert and national reports, local reports and anecdotal evidence, or not known). The sources of evidence used were placed in these categories by two researchers independently, with discussion of and agreement on the results. Respondents usually cited more than one source of evidence for each change (e.g., an expert report plus journal publication). Each source of evidence was counted separately to give an overall perception of the pattern of evidence accessed. This method underestimates the 'not known' category, which was stated only once for any service change.

\section{Results}

Perceived contribution of evidence, and types of evidence used to support changes to purchased services

A total of 24 examples of service changes were presented. In total, $10(83 \%)$ of the 12 health authority examples were categorized as 'diseasespecific' changes and two (17\%) as 'nondisease- 
specific/organizational' changes. For TPPs, six examples $(50 \%)$ were disease-specific and six were nondisease-specific.

The diseases for which changes were mentioned were diabetes $(n=5)$, cardiovascular disease $(n=2)$, mental health $(n=2)$, infertility $(n=2)$, cancer $(n=2)$ and other $(n=3)$. Nondisease-specific changes included shifting services to primary care $(n=3)$, altering prescribing patterns $(n=2)$ and other $(n=3)$. Figure 1 shows the contribution of evidence to disease-specific and nondisease-specific changes for health authorities and TPPs. For both health authorities and TPPs, the contribution of evidence was less for the nondisease-specific than for the disease-specific changes. Evidence appears to play a smaller role in changes made to disease-specific services for TPPs than for the health authorities.

More high-quality evidence was used in support of disease-specific changes by both health authorities and TPPs (see Figure 2). TPPs used higher quality evidence for nondisease-specific changes than did health authorities, but health authorities only gave two examples of nondisease-specific changes. The opposite was true for diseasespecific changes.

Differences between health authorities and total purchasing pilots with regard to deciding upon changes to purchased and provided services: contribution of evidence and type of evidence used

The impact of evidence was greater for changes made by health authorities. For $80 \%$ of their changes in purchased services, evidence played a

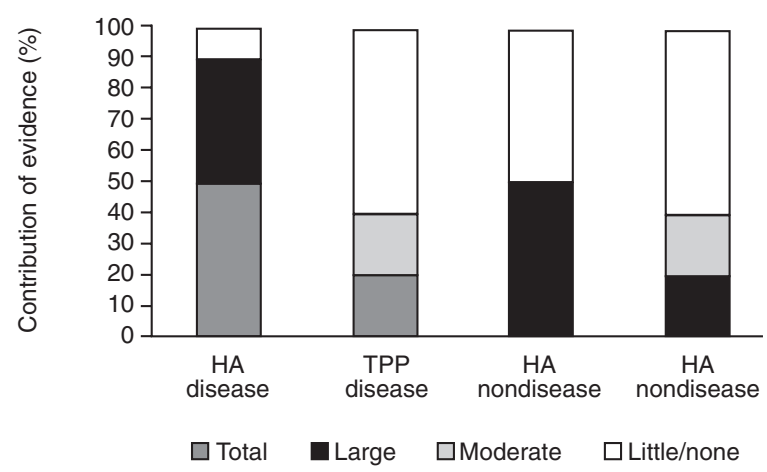

Figure 1 Perceived contribution of evidence to diseasespecific and nondisease-specific changes to purchased services for health authorities and total purchasing pilots.

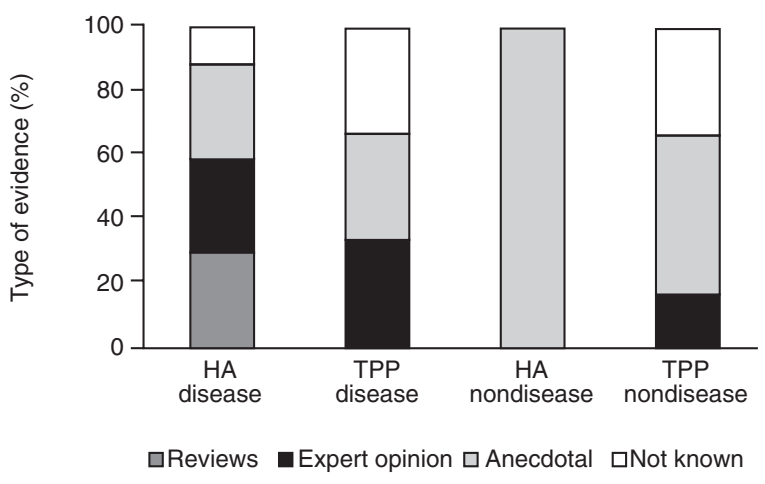

Figure 2 Perceived type of evidence used in changes to disease-specific and nondisease-specific services purchased by health authorities and total purchasing pilots.

large part or was the sole reason for the change, whereas for the TPPs $60 \%$ of the changes to purchased services used little or no evidence (see Figure 3 ). For changes to care provided by TPPs, evidence was the sole reason or a large part of the reason behind the change in all examples given.

Figure 4 compares the types of evidence used. Health authorities used an even spread of reviews, expert reports and local/anecdotal evidence, with about $10 \%$ of sources of evidence being unknown. TPPs did not report using trials or reviews for changes they made to purchased services; they used local reports or opinions. For the TPPs' changes to provided services, there was greater use of published trials or reviews and expert reports.

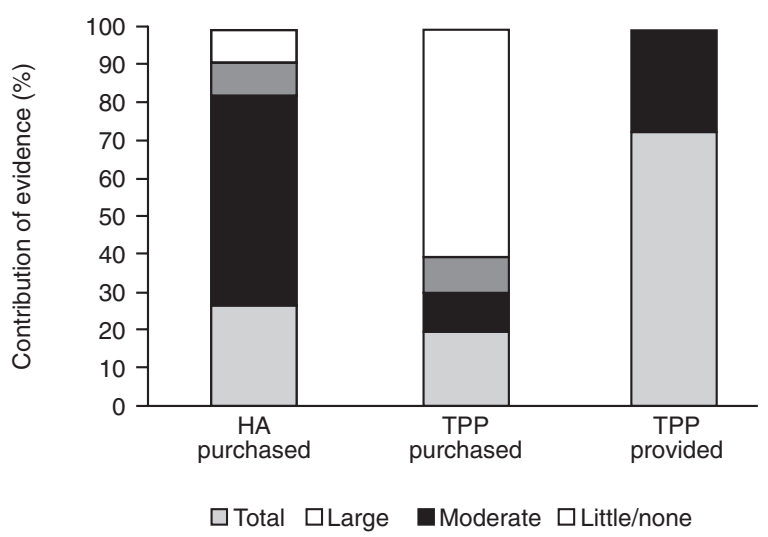

Figure 3 Perceived contribution of evidence to changes purchased by health authorities, and changes purchased and provided by total purchasing pilots. 


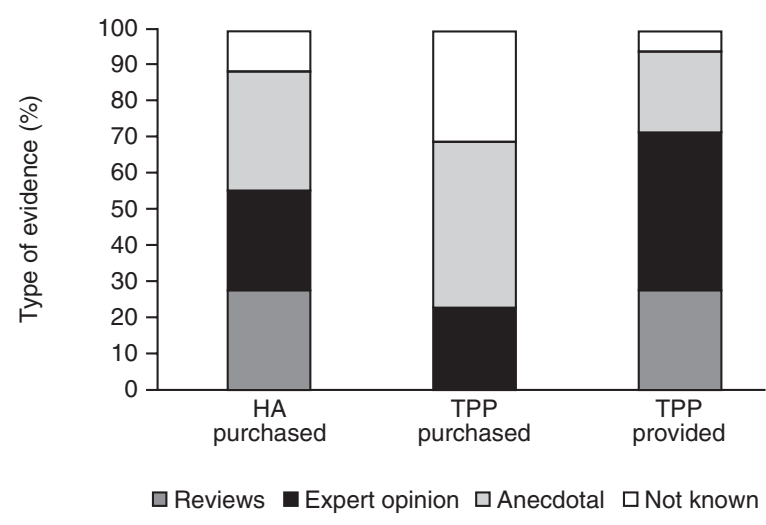

Figure 4 Perceived type of evidence used for changes purchased by health authorities and purchased and provided by total purchasing pilots.

\section{Views of evidence}

Three of the four interviewees for both health authorities and TPPs thought that evidence-based medicine had influenced their purchasing and provision of health care (in ways other than service changes) through a generally increased awareness. One health authority had increased its audits of clinical effectiveness to standardize treatments. In general, the TPPs thought that evidence-based medicine had made GPs more critical when reading published papers, and more aware of their need for appropriate education and training in evidencebased medicine.

The public health medicine physicians were more enthusiastic than the GPs about the value of evidence-based medicine for commissioning services in the future, regarding it as either essential or very useful, but recognizing that it would only be of great value in situations where it produced a clear-cut decision. The GPs felt that it had little or only moderate value for commissioning services, but that it would have an impact on their provision of care. They expressed concern about the overuse of guidelines, particularly those that were not evidence based.

\section{Constraints that general practitioners}

\section{experienced with regard to using evidence}

The main sources of evidence that GPs used on a regular basis were journals held in their practice libraries (examples given were Bandolier, Update and Clinical Effectiveness Matters). Some evidence was obtained from the Internet, although they expected this to increase with access to the NHS Wales Intranet. For purchased service changes, they used reports from pilot schemes elsewhere and information from the local public health medicine department.

General practitioners experienced some difficulty in finding and using evidence. All four GP responders mentioned lack of time as the major constraint. Lack of (or irregular) public health medicine support and inability to find appropriate information were also important factors. Two GPs would have liked to spend more time reviewing the clinical effectiveness literature, despite receiving good support from the public health medicine department. Regular public health medicine support had been lost from one pilot, and their clinical effectiveness meetings had suffered as a result. One GP was concerned about the difficulty in finding evidence about specialist areas, and was unclear as to where the public health medicine doctors found the information that they used.

Table 1 shows the sources of evidence and training available. Respondents were unable to say whether these services were new facilities that had been made available as a result of total purchasing. All of the GPs thought that training about the sources of, and access to, available evidence and how to undertake computer searches would be helpful to TPPs, although one GP thought that public health doctors should provide information on evidence to GPs.

Table 1 Sources of evidence and training available to pilots and health authorities $(n=4)$

\begin{tabular}{lll}
\hline & TPPa & $\begin{array}{l}\text { Health } \\
\text { authority }^{\text {a }}\end{array}$ \\
\hline Attended external courses & 2 & 3 \\
Set up in-house training & 3 & 3 \\
Access to literature search facilities & 2 & 4 \\
Subscribe to journals & 3 & 4 \\
Access to Internet & 3 & 4 \\
Access to Cochrane Library & 2 & 4 \\
Other & 2 & 4 \\
\hline
\end{tabular}

a Based on answers from four GPs and four health authority public health medicine doctors (i.e., denominator four in each column). 


\section{Discussion}

Our study had two main limitations. First, interviewees were asked to select three examples of changes. The examples that they chose may not constitute a complete picture of recent decisions. For example, they may illustrate good use or little use of evidence. However, it is difficult to obtain a complete picture. For example, searching contract agreements would, of course, only capture changes specified in contracts, and would not have identified changes in care provided by GPs. Secondly, we relied upon opinions expressed by one GP or one public health medicine doctor on the contribution of evidence (ranging from none to the total reason for the change). Other respondents might have interpreted the impact of the evidence differently. Despite these limitations, our findings raise several important issues.

Total purchasing pilots were created by GPs who were interested in extending their scope of commissioning to change services for their patients. Our respondents were chosen for their interest in, or knowledge of, the use of evidence. Thus they are unlikely to be representative of general practice or public health medicine as a whole. As all GPs in England and Wales are now required to be part of a PCG or LHG, the evidence they are using to commission changes in services is likely to be less adequate than that reported in our study.

In their comparison of commissioning decisions by health boards and GPs in Scotland, Farmer and Williams found that the quality of evidence cited by public health physicians in support of nondisease-specific changes was poorer than that cited by GPs (Farmer and Williams, 1997). Our respondents perceived that quality of evidence (where publication is a proxy for quality) was higher for commissioning disease-specific changes and changing services provided by primary care than for commissioning other types of services. This is probably due to the ease of access to published evidence on specific diseases. Stocking (1995) argued that the reason why health authorities did not use research evidence to inform commissioning was that research findings were unavailable when needed for decision making or that, when they were available, they were in the wrong format.

General practitioners' awareness of evidencebased medicine, which ought to be a key element of clinical governance, has increased in recent years. The GPs in this study were more critical in their reading, and wanted more training. There is currently debate about the future direction of continuing professional development in primary care (Department of Health, 1998b), and primary care educators should address the need for training in the quality of evidence. Developments in information technology, such as PRODIGY and the NHS Information Strategy, may help primary health care teams to gain access to evidence-based medicine. Access to the Internet, which the TPPs had, will enable them to undertake their own literature searches and obtain appropriate information. However, many GPs will want accessible summaries of evidence (McColl et al., 1998).

However, our research into total purchasing has shown that, in a primary-care-led NHS, even if GPs were to have easy access to evidence, there is a mismatch between the availability of conventional evidence and the need for other types of evidence for commissioning changes in the organization of services. Conventional evidence is diseasespecific and aimed predominantly at clinical practice. This forms the majority of the evidence that is published in peer-reviewed medical journals. Local health groups and primary care groups will probably continue to seek changes in services that are not based on conventional evidence, but which result from multiple influences outside standard research frameworks.

The issue is that a change in commissioning services could still produce significant benefits in the absence of conventional evidence. This suggests both a short-term conflict and a long-term priority. The short-term conflict is that of seeking to reorganize the NHS so that commissioning is led by primary care, but with improvements in the quality of care as measured by conventional evidence. The conflict arises because conventional evidence will be incapable of assessing primary care-led commissioning that produces changes which are likely to be beneficial. The long-term priority is for NHS Research and Development to encourage the evaluation of commissioning changes in the organization of services. This will require both empirical and methodological work, because outcomes are difficult to measure for organizational changes that affect patients with different diseases. 


\section{Acknowledgements}

We are grateful to the members of the total purchasing pilots and health authorities for giving up their time for this study. We also wish to thank Professor Debbie Sharp and an anonymous referee for some valuable comments on an earlier draft. This study was funded by the Welsh Office.

All of the authors were members of the Total Purchasing National Evaluation Team (TP-NET), which included researchers from the King's Fund Policy Institute, the National Primary Care R\&D Centre, the Universities of Edinburgh, Bristol, Southampton, York and Birmingham, the London School of Hygiene and Tropical Medicine, and the London School of Economics and Political Science. More information about the evaluation is available from the King's Fund Policy Institute, 11-13 Cavendish Square, London W1M 0AN.

\section{References}

Department of Health 1997: The new NHS: modern, dependable. London: The Stationery Office.

Department of Health 1998a: Putting patients first. Cardiff: The Stationery Office.

Department of Health 1998b: A review of continuing professional development in general practice. A report by the Chief Medical Officer. London: Department of Health.

Ellis, J., Mulligan, I., Rowe, J. and Sackett, D.L. 1995: Inpatient general medicine is evidence based. Lancet 346, 407-10.
Farmer, J. and Williams, D. 1997: Decision-making by healthpurchasing organisations in Scotland: the role and influence of evidence from the literature. Journal of Information Science 23, 59-72.

Gill, P., Dowell, A.C., Neal, R.D., Smith, N., Heywood, P. and Wilson, A.E. 1996: Evidence-based general practice: a retrospective study of interventions in one training practice. British Medical Journal 312, 819-21.

Killoran, A., Mays, N., Wyke, S. and Malbon, G. 1999: Total purchasing: a step towards primary care organisations. London: King's Fund Publishing.

Lehman, R. 1999: In praise of hunch backing. British Medical Journal 319, 1143.

McColl, A., Smith, H., White, P. and Field, J. 1998: General practitioners' perceptions of the route to evidence-based medicine: a questionnaire survey. British Medical Journal 316, 361-65.

Mahon, A., Stoddart, H., Leese, B. and Baxter, K. 1998: How do total purchasing projects inform themselves for purchasing? London: King's Fund Publishing.

Mays, N., Goodwin, N., Bevan, G. and Wyke, S. 1997: Total purchasing. A profile of national pilot projects. London: King's Fund Publishing.

NHS Centre for Reviews and Dissemination 1996: Undertaking systematic reviews of research effectiveness. CRD guidelines for those carrying out or commissioning reviews. York: NHS Centre for Reviews and Dissemination, University of York.

NHS Executive 1999: Improving quality and performance in the new NHS: clinical indicators and high-level performance indicators. Leeds: NHS Executive.

Sackett, D., Rosenberg, W.M.C., Gray, J.A.M., Haynes, B. and Richardson, W.S. 1996: Evidence-based medicine: what is it and what isn't it? British Medical Journal 312, 71-72.

Stocking, B. 1995: Why research findings are not used by commissions - and what can be done about it. Journal of Public Health Medicine 17, 380-82. 


\section{Appendix 1 GP Interview: use of EBM and HNA and relations with PHM (face-to- face interview, February/March 1998)}

\section{Sources of information}

\section{Important - please read this before completing the questionnaire}

Evidence-based medicine (EBM) is defined as the conscientious, explicit and judicious use of current best evidence in making decisions about the care of individual patients or when purchasing care for groups of patients. It involves tracking down the best external evidence with which to answer clinical or purchasing questions, critically appraising this evidence and using it to inform decision making or practice (e.g., systematic reviews in which published and unpublished studies are used).

1a Are you conscious of the TPP using evidence in decision making?

Yes
No
Don't know

1b If yes, list the $\mathbf{4}$ main sources of evidence used and where the TPP obtains these:

Main sources of evidence

(e.g., effective health-care bulletin)

2.

3.

4.

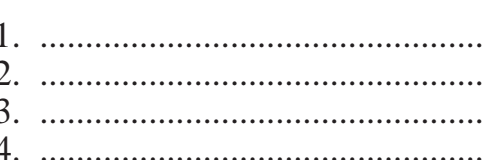

Where obtained

(e.g., practice library, Internet)

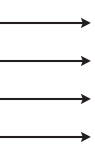

2 Are you aware of other sources of evidence which the TPP would like to use? Please describe what these are and why you do not currently use them. 
3a Is your TPP investing in finding and using EBM?

\section{Yes \\ No \\ Don't know}

3b If yes, what has been done?

Don't know

Courses outside the TPP attended

In-practice training (critical appraisal skills, etc.)

Literature searches available in TPP

Subscription to journals

Internet resources

Cochrane Library

Other (please specify)

4a Has EBM been discussed at TPP meetings?

Yes, about specific services or clinical decisions

Yes, but only the general concept

No, we have not discussed it

It is left to individual practices to discuss EBM

Don't know

4b If yes, how often has EBM been discussed at these meetings?

Always

Almost always

Sometimes

Rarely

Never 
The provision of individual clinical care

5a Has your TPP made policy changes concerning the treatment and care of individual patients in the last 2 years?

(such as changing the drugs prescribed for depression)

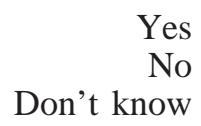

5b If yes, please give details in the table below of up to three such changes. Please describe:

- what the main clinical changes were (e.g., changes in care for asthma);

- the year in which the change was or will be implemented;

- your reasons for the change;

- the contribution of EBM to the change;

- the type of EBM used.

\begin{tabular}{|c|c|c|c|}
\hline & 1. Service change & 2. Service change & 3. Service change \\
\hline \multicolumn{4}{|l|}{ Nature of the change } \\
\hline \multicolumn{4}{|l|}{ Year of implementation } \\
\hline \multicolumn{4}{|c|}{$\begin{array}{l}\text { Main reasons for the change } \\
\text { (or write don't know) }\end{array}$} \\
\hline $\begin{array}{l}\text { Contribution of EBM to } \\
\text { the change (if any) }\end{array}$ & $\begin{array}{l}\text { Nil } \square \\
\text { Very little } \square \\
\text { Moderate amount } \square \\
\text { Large amount } \square \\
\text { Sole reason } \square \\
\text { Don't know } \square\end{array}$ & $\begin{array}{l}\text { Nil } \square \\
\text { Very little } \square \\
\text { Moderate amount } \square \\
\text { Large amount } \square \\
\text { Sole reason } \square \\
\text { Don't know } \square\end{array}$ & $\begin{array}{l}\text { Nil } \square \\
\text { Very little } \square \\
\text { Moderate amount } \square \\
\text { Large amount } \square \\
\text { Sole reason } \square \\
\text { Don't know } \square\end{array}$ \\
\hline $\begin{array}{l}\text { EBM used (if any) (e.g. } \\
\text { systematic review) }\end{array}$ & & & \\
\hline
\end{tabular}


6a Has EBM influenced your behaviour as GPs in other ways? (it may have increased/decreased your attendance at postgraduate meetings/seminars/courses or encouraged self-directed education, audit, links with universities, research and development, etc.)

$$
\begin{array}{r}
\text { Yes } \\
\text { No } \\
\text { Don't know }
\end{array}
$$

6b Describe what influence EBM has had on you as GPs:

1.

2

3.

7a Do you feel that EBM will help you as GPs to treat and care for individual patients in the future?

$$
\text { Yes }
$$

No

Don't know

7b If yes, how helpful do you think it will be?

EBM will help a little EBM will help a moderate amount EBM will help a great deal EBM will be essential

7c If it will not help, why is this? 


\section{Purchasing health care}

8a With regard to the purchasing of health care from other providers, has the TPP made any service changes in the past 2 years?

We do not purchase health care

8b If yes, please give details in the table below of up to three such changes. Please describe:

- what the main service changes were (there may have been a change in provider, location of service, the organization of a service, etc.);

- the year in which the change was or will be implemented;

- the $\operatorname{reason}(\mathbf{s})$ for the change;

- the contribution of EBM to the change;

- the type of EBM used.

\begin{tabular}{|c|c|c|c|}
\hline & 1. Service change & 2. Service change & 3. Service change \\
\hline Nature of the change & & & \\
\hline Year of implementation & & & \\
\hline $\begin{array}{l}\text { Main reasons for the change } \\
\text { (or write don't know) }\end{array}$ & & & \\
\hline $\begin{array}{l}\text { Contribution of EBM to } \\
\text { the change (if any) }\end{array}$ & $\begin{array}{l}\text { Nil } \square \\
\text { Very little } \square \\
\text { Moderate amount } \square \\
\text { Large amount } \square \\
\text { Sole reason } \square \\
\text { Don't know } \square\end{array}$ & $\begin{array}{l}\text { Nil } \square \\
\text { Very little } \square \\
\text { Moderate amount } \square \\
\text { Large amount } \square \\
\text { Sole reason } \square \\
\text { Don't know } \square\end{array}$ & $\begin{array}{l}\text { Nil } \square \\
\text { Very little } \square \\
\text { Moderate amount } \square \\
\text { Large amount } \square \\
\text { Sole reason } \square \\
\text { Don't know } \square\end{array}$ \\
\hline $\begin{array}{l}\text { EBM used (if any) (e.g. } \\
\text { systematic review) }\end{array}$ & & & \\
\hline
\end{tabular}


9 It may be difficult to link EBM to specific service changes, but EBM may have influenced the TPP's purchase of health care in other ways (e.g., development of guidelines with providers, audit, collection of data, contract negotiations, discussions about the quality of care, needs assessment, work with the health authority, etc.)

9a Has EBM influenced the TPP in other ways?

\section{Yes \\ No \\ Don't know}

9b How has EBM influenced the TPP?

1 .

2.

3.

10a Do you feel that EBM will help you in the future as part of a local health group?

Yes
No
Don't know

10b If yes, how helpful do you think it will be?

EBM will help a little EBM will help a moderate amount EBM will help a great deal EBM will be essential

10c If it will not help, why is this? 
11 Would you find any of the following helpful?

Helpful

Training in: a) critical appraisal skills

b) sources of evidence available

c) computer searches

Advice in EBM from:

a) public health medicine physicians within the primary care setting

b) public health medicine physicians from the health authority

c) someone else (please state who)

Which of the following facilities are available in your practice/TPP?

a) Written summaries of available evidence

b) Computer searches

c) Journals and books

d) Databases (e.g., Cochrane database)

e) Internet

Would anything else be helpful?

(Please describe below) 


\section{Appendix 2 HA Interview: use of EBM and HNA and relations with TPP (face-to- face interview, February/March 1998)}

\section{Sources of information}

Evidence-based medicine is defined as the conscientious, explicit and judicious use of current best evidence in making decisions about the care of individual patients or when purchasing care for groups of patients. It involves tracking down the best external evidence with which to answer clinical or purchasing questions, critically appraising this evidence and using it to inform decision making or practice.

1a Are you conscious of using evidence in HA decision making?

\section{Yes \\ No \\ Don't know}

4a Has the authority invested in finding and using clinical effectiveness information?

\section{Yes \\ No \\ Don't know}

Go to question 5

4b If yes, what has been done?

Don't know

External courses attended

In-house training set up (e.g., in critical appraisal skills)

Library resources (e.g., ability to do searches)

Subscription to journals

Internet resources

Other (please specify)

Is the HA linking or involved in any national or local initiatives?

(e.g., NHS Wales Clinical Effectiveness Initiative, NICE Project, NHS Wales Intranet) 
5a Has effectiveness information or EBM been discussed at board meetings?

Yes, about specific services or clinical decisions Yes, but only the general concept No, we have not discussed it Don't know

Go to Question 6

5b If yes, how often has EBM been discussed at these meetings?

Always
Almost always
Sometimes
Rarely
Never

Primary Health Care Research and Development 2001; 2: 7-24 
6a Has the authority been involved with any decisions to change services in the last $\mathbf{2}$ years?

$$
\begin{array}{r}
\text { Yes } \\
\text { No } \\
\text { Don't know }
\end{array}
$$

6b If yes, please give details in the table below of up to three such changes. Please describe:

- what the main service changes were (there may have been a change in provider, location of service, the organization of a service, etc.);

- the year in which the change was or will be implemented;

- the reason(s) for the change;

\begin{tabular}{|c|c|c|c|}
\hline & 1. Service change & 2. Service change & 3. Service change \\
\hline \multicolumn{4}{|l|}{ Nature of the change } \\
\hline \multicolumn{4}{|l|}{ Year of implementation } \\
\hline \multicolumn{4}{|l|}{$\begin{array}{l}\text { Main reasons for the change } \\
\text { (or write don't know) }\end{array}$} \\
\hline $\begin{array}{l}\text { Contribution of EBM to } \\
\text { the change (if any) }\end{array}$ & $\begin{array}{l}\text { Nil } \square \\
\text { Very little } \square \\
\text { Moderate amount } \square \\
\text { Large amount } \square \\
\text { Sole reason } \square \\
\text { Don't know } \square\end{array}$ & $\begin{array}{l}\text { Nil } \square \\
\text { Very little } \square \\
\text { Moderate amount } \square \\
\text { Large amount } \square \\
\text { Sole reason } \square \\
\text { Don't know } \square\end{array}$ & $\begin{array}{l}\text { Nil } \square \\
\text { Very little } \square \\
\text { Moderate amount } \square \\
\text { Large amount } \square \\
\text { Sole reason } \square \\
\text { Don't know } \square\end{array}$ \\
\hline $\begin{array}{l}\mathrm{EBM} \text { used (if any) (e.g. } \\
\text { systematic review) }\end{array}$ & & & \\
\hline
\end{tabular}

- the contribution of EBM to the change;

- the type of EBM used. 
7 It may be difficult to link EBM to specific service changes, but EBM may have influenced the authority's purchase of health care in other ways (e.g., development of guidelines with providers, audit, local research, contract negotiations, discussions about the quality of care, needs assessment, work with other purchasers)

7a Has EBM has influenced the authority in other ways?

7b How has EBM influenced the authority?

\section{Don't know}

1 .

2

3.

8a Do you feel that EBM will help the authority in the future as a purchaser of health care?

$$
\begin{array}{r}
\text { Yes } \\
\text { No } \\
\text { Don't know }
\end{array}
$$

8b If yes, how helpful do you think it will be?

EBM will help a little EBM will help a moderate amount EBM will help a great deal EBM will be essential

8c If it will not help, why is this? 